\section{Immunohistochemical demonstration of specific antigens in the human brain fixed in zinc-ethanol- formaldehyde}

\section{D.E. Korzhevskii, E.G. Sukhorukova, O.V. Kirik, I.P. Grigorev}

Laboratory of Functional Morphology of the Central and Peripheral Nervous System, Department of General and Specific Morphology, Institute of Experimental Medicine, St. Petersburg, Russia

\begin{abstract}
Tissue fixation is critical for immunohistochemistry. Recently, we developed a zincethanol-formalin fixative (ZEF), and the present study was aimed to assess the applicability of the ZEF for the human brain histology and immunohistochemistry and to evaluate the detectability of different antigens in the human brain fixed with ZEF. In total, 11 antigens were tested, including NeuN, neuronspecific enolase, GFAP, Iba-1, calbindin, calretinin, choline acetyltransferase, glutamic acid decarboxylase (GAD65), tyrosine hydroxylase, synaptophysin, and $\alpha$-tubulin. The obtained data show that: i) the ZEF has potential for use in general histological practice, where detailed characterization of human brain morphology is needed; ii) the antigens tested are well-preserved in the human brain specimens fixed in the ZEF.
\end{abstract}

\section{Introduction}

Morphological studies of the human brain are commonly conducted on nervous tissue obtained in autopsy. Quality of the obtained material critically depends on post-mortem time and the fixative chosen. Early autopsy is not always available because of ethical considerations and, accordingly, the fixation became the most crucial step in the preparation of the human brain tissue for morphological observation. The fixation is required to prevent the specimens from the undergoing autolysis (the degradation of macromolecules including proteins and nucleic acids) and decomposition. On the other hand, the fixation must preserve the antigenic properties of the proteins making available their immunohistochemical labeling.
Brain specimens fixed in ethanol or neutral buffered formalin have conventionally been used for classic histological examination with various histological stains. However, both fixatives have disadvantages in immunohistochemistry, because formalin as an electrophilic substance forms crosslinks with reactive functional groups in proteins, nucleic acids, and other macromolecules and, thus, the sterically modified epitopes may have compromised immunoreactivity, ${ }^{1-3}$ whereas ethanol does not form crosslinks, but fixes the tissue by precipitation and the ethanol-fixed tissues showed contraction of the cells. ${ }^{4}$ Therefore, the ethanol-, or formalin-fixed human brain specimens demonstrate bad antigenicity, which impedes or even makes it is impossible the immunohistochemical investigation of the tissue. Moreover, the neutral buffered formalin was found to be the poorest fixative for maintaining antigen recognition by immunohistochemistry and the ethanol was also bad for all antigens used. ${ }^{5,6}$ Therefore, a search for alternative fixatives, which offers better preservation of the histology and antigenicity of different organs, has intensively been carried out from the 1990 s. $^{7-15}$

Recently, encouraging data have been published that zinc-containing fixatives augment the antigenicity of the tissue and improves the intensity of immunolabeling for some antigens. ${ }^{4,5,16-22}$ Based on these data, we have developed a zinc-containing fixative as a mixture of zinc (as a zinc chloride), ethanol, and formalin and used it successfully for histological and immunohistochemical study of the brain and peripheral tissues of the rat and rabbit. ${ }^{23-32}$

The aim of the present study was to assess the preservation of different antigens in the human brain fixed in the zinc-ethanol-formalin and the detectability of the antigens using immunohistochemistry performed with various antibodies. The antibodies chosen were those that are conventionally used to label the certain cell type (neurons, glia, ependymocytes), or to show the neurotransmitter specificity of the nerve cells and synapses in the brain.

\section{Materials and Methods}

\section{Human brain specimens}

Brains were obtained at autopsy from neurologically normal individuals (case details are shown in Table 1). The following brain areas were used in the study: precentral gyrus of parietal lobe, the head and body of the caudate nucleus, substantia nigra, nucleus ruber, cerebellar cortex, and, additionally, a thoracic sympathetic ganglion of the sympathetic trunk. The study program was positively approved by
Correspondence: Dr. Igor P. Grigorev, Laboratory of Functional Morphology of the Central and Peripheral Nervous System, Department of General and Specific Morphology, Institute of Experimental Medicine, Ulitsa Akademika Pavlova, 12, St. Petersburg, 197376 Russia. Tel. +7.812.2342438 - Fax: +7.812.2349489. E-mail: ipg-iem@yandex.ru

Key words: Fixation; zinc-ethanol-formalin; immunohistochemistry; human brain.

Contributions: DEK, design, critical review, data collection, analysis and interpretation, draft of manuscript, final approval; EGS, data collection, analysis and interpretation, draft of manuscript, final approval; OVK, data collection, analysis and interpretation, final approval; IPG, design, data analysis and interpretation, critical literature review, draft of manuscript, final approval.

Conflict of interest: the authors declare that there is no conflict of interest that could be perceived as prejudicing the impartiality of the research reported.

Funding: this study was supported by the Russian Science Foundation (grant no. 14-15-00014).

Received for publication: 23 April 2015. Accepted for publication: 23 July 2015.

This work is licensed under a Creative Commons Attribution NonCommercial 3.0 License (CC BYNC 3.0).

(C) Copyright D.E. Korzhevskii et al., 2015

Licensee PAGEPress, Italy

European Journal of Histochemistry 2015; 59:2530 doi:10.4081/ejh.2015.2530

the local Ethics Committee of the Institute of Experimental Medicine, (St. Petersburg, Russia).

\section{Tissue preparations}

The autopsy tissue was immediately sectioned to approximately 10x10x10-mm blocks and placed into the zinc-ethanol-formalin fixative (ZEF). The ZEF was prepared as follows: 1 $\mathrm{g} \mathrm{ZnCl}_{2}$ was dissolved in mixture of $90 \mathrm{~mL} 96 \%$ ethanol and $10 \mathrm{~mL}$ concentrated (35-39\%) formaldehyde (all purchased from Vekton, St. Petersburg, Russia). Two brain specimens (males, 46 and 51 years-old, post-mortem interval $96 \mathrm{~h}$ ) were fixed in 10\% neutral buffered formalin (Vekton, St. Petersburg, Russia).

After fixation for $24 \mathrm{~h}$ at room temperature the blocks were dehydrated and embedded in paraffin routinely. Sections 5 or $10 \mu \mathrm{m}$ thick were cut using rotary or sliding microtome (RM 2125RT and SM 2000R, respectively; Leica, Wetzlar, Germany) and mounted on poly-L-lysine-coated (Polysine $^{\mathrm{TM}}$, MenzelGläser, Germany) or silane treated 
(HistoBond $^{\mathrm{R}}$, Marienfeld, Germany) glass slides.

\section{Immunohistochemistry}

For immunohistochemistry the sections were deparaffinized and rehydrated routinely. The heat-induced antigen retrieval was carried out by incubating the sections in modified citrate buffer, pH 6.1 (S1700, Dako, Glostrup, Denmark) in a conventional steamer, which steam chamber size allows putting in a Hellendahl jar with the slides, for 25 min. The heat-induced antigen retrieval was omitted for choline acetyltransferase, NeuN, and neuronspecific enolase antibodies. The preparations were pretreated with the blocking solution (Protein Block, Spring Bioscience) and then a primary antibody was applied (details in Table 2). To visualize the applied primary antibodies the following reagents were used: for mouse monoclonal antibodies, MACH2 Mouse HRPPolymer (Biocare Medical, Concord, CA, USA); for rabbit mono- and polyclonal antibodies, Reveal Polyvalent HRP DAB (Spring Bioscience, Pleasanton, CA, USA); for goat antibodies, biotinylated anti-goat antibody (Dako) and streptavidin conjugated with HRP (streptavidin/horse radish peroxidase; Spring Bioscience). Control of the immunocytochemical reaction was performed according to the recommendation of the reagent manufacturers. All the preparations were counterstained with alum hematoxylin or astra blue and were examined with a Leica DM 750 microscope and photographed with Leica ICC 50 digital camera (Leica) operated by LAS EZ software (ver. 1.8.0, Leica Microsystems, Heerbrugg, Switzerland).

\section{Results}

\section{Histological examination}

ZEF-fixed brain preparations were initially Nissl-stained with conventional stains (not shown) and showed good preservation of the nervous tissue obtained from all the studied brain areas, and superior staining of neurons, glial, and endothelial cells. Shrinkage of tissues and swelling of cells was rarely observed and the histology of the brain sections examined was judged to be adequate for research and diagnostic purposes.

\section{Immunohistochemical visualization of antigens}

Usage of various immunohistochemical markers demonstrated a pronounced

Table 1. Cases and tissue history.

\begin{tabular}{lcccc} 
Case no. & Sex & Age (years) & Cause of death & PMI (h) \\
1 & Male & 25 & Massive blood loss & 15 \\
2 & Male & 30 & Massive blood loss & 20 \\
\hline 3 & Male & 34 & Mechanical asphyxia & 24 \\
4 & Male & 39 & Acute severe asthma & 24 \\
\hline 5 & Female & 42 & Massive blood loss & 24 \\
6 & Male & 46 & Acute cardiac failure & 24 \\
\hline 7 & Male & 46 & Acute cardiac failure & 12 \\
8 & Female & 48 & Aortic rupture & 21 \\
\hline 9 & Male & 58 & Acute cardiac failure & 24 \\
10 & Male & 60 & Acute cardiac failure & 24 \\
\hline 11 & Female & 78 & Colorectal cancer & 18 \\
12 & Male & 89 & Colorectal cancer & 72 \\
\hline
\end{tabular}

PMI, post-mortem interval.

Table 2. Characteristics of the antibodies used and details of their application.

\begin{tabular}{|c|c|c|c|}
\hline Antigens & $\begin{array}{l}\text { Antibodies } \\
\text { (species, clonity, manufacturer, } \\
\text { catalogue number, dilution) }\end{array}$ & $\begin{array}{l}\text { tion and temperature of } \\
\text { ibation with antibodies }\end{array}$ & Visualization \\
\hline Calbindin & $\begin{array}{l}\text { Mouse monoclonal (clone CL-300); } \\
\text { Abcam, Cambridge, UK; ab9481; 1:100 }\end{array}$ & $100 \min , 40^{\circ} \mathrm{C}$ & MACH2 \\
\hline Calretinin & Rabbit polyclonal; Spring Bioscience; E1170; 1:100 & $30 \min , 40^{\circ} \mathrm{C}$ & HRP-conjugate \\
\hline $\begin{array}{l}\text { Choline } \\
\text { acetyltransferase (ChAT) }\end{array}$ & $\begin{array}{l}\text { Goat polyclonal; Merck Millipore, } \\
\text { Billerica, MA, USA; AB144P; 1:250 }\end{array}$ & Overnight, $27^{\circ} \mathrm{C}$ & Anti-Gt-Bio+Str/HRP* \\
\hline $\begin{array}{l}\text { Glutamic acid decarboxylase } \\
\text { (GAD65) }\end{array}$ & Rabbit polyclonal; Spring Bioscience; E3310; 1:100 & $30 \min , 40^{\circ} \mathrm{C}$ & HRP-conjugate \\
\hline $\begin{array}{l}\text { Glial fibrillary acidic protein } \\
\text { (GFAP) }\end{array}$ & $\begin{array}{l}\text { Mouse monoclonal (clone SPM507); } \\
\text { Spring Bioscience; E16510; 1:100 }\end{array}$ & $60 \mathrm{~min}, 40^{\circ} \mathrm{C}$ & MACH2 \\
\hline Iba-1 protein (AIF1) & Goat polyclonal; Abcam; ab5076; 1:200 & overnight, $27^{\circ} \mathrm{C}$ & Anti-Gt-Bio+Str/HRP* \\
\hline NeuN protein & $\begin{array}{l}\text { Mouse monoclonal (clone A60); Chemicon, } \\
\text { Temecula, CA, USA; AB377; 1:400 }\end{array}$ & $60 \mathrm{~min}, 40^{\circ} \mathrm{C}$ & MACH2 \\
\hline Neuron-specific enolase (NSE) & Rabbit polyclonal; Chemicon; AB951; 1:250 & $30 \mathrm{~min}, 40^{\circ} \mathrm{C}$ & HRP-conjugate \\
\hline Synaptophysin & monoclonal (clone SP11); Spring Bioscience; M3110; 1:100 & $60 \min , 40^{\circ} \mathrm{C}$ & HRP-conjugate \\
\hline Tyrosine hydroxylase & $\begin{array}{l}\text { Rabbit polyclonal; Abcam; ab112; 1:1000 } \\
\text { Mouse monoclonal (clone 1B5); Leica-Novocastra, } \\
\text { Newcastle-upon-Tyne, UK; NCL-TH36011; 1:50 }\end{array}$ & $\begin{array}{l}60 \min , 40^{\circ} \mathrm{C} \\
60 \min , 40^{\circ} \mathrm{C}\end{array}$ & $\begin{array}{l}\text { HRP-conjugate } \\
\text { MACH2 }\end{array}$ \\
\hline$\alpha$-Tubulin & $\begin{array}{l}\text { Mouse monoclonal (clone DM-1A); } \\
\text { BioGenex, Fremont, CA, USA; MU121-UC; 1:100 }\end{array}$ & $60 \min , 40^{\circ} \mathrm{C}$ & MACH2 \\
\hline
\end{tabular}

MACH2, mouse HRP-Polymer (Biocare Medical); HRP-conjugate from Reveal Polyvalent HRP DAB s(Spring Bioscience); *biotinylated anti-goat antibody (Dako) and streptavidin conjugated with HRP (streptavidin/horse radish peroxidase; Spring Bioscience). 
immunostaining of cells and/or fibers in all the examined brain areas (Figure 1). Minimal background staining ensured a contrastive and reproducible image of the immunostained tissue. Quality of images was good irrespectively the counterstaining with hematoxylin or astra blue. We failed to find any visible differences in quality of both histological and immunohis- tochemical preparations in relation to the postmortem interval of the brain specimens used in this study.

Differential intracellular immunoreactivity was observed, e.g., tyrosine hydroxylase antibodies clearly labeled cytoplasm to greater extent than the nucleus, while the opposite was true for the NeuN. Cell-specific
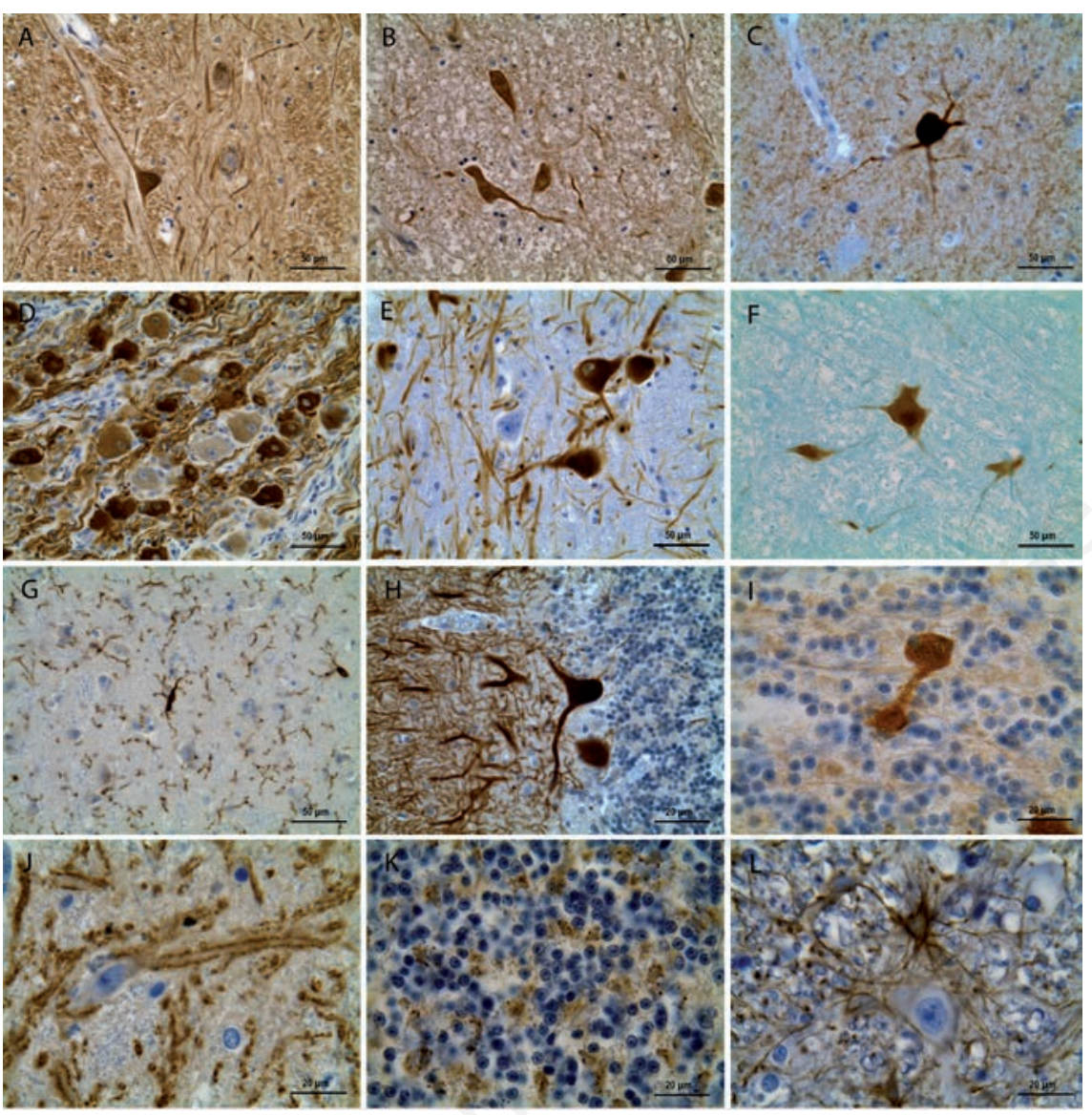

Figure 1. Examples of immunohistochemical staining of the human brain fixed in the ZEF. A) Substantia nigra, pars reticulata: $\alpha$-tubulin in the single neuron with extensively stained perikaryon and processes, many immunoreactive fibers in the surrounding neuropil. B) Nucleus ruber: extensive neuron-specific enolase (NSE) immunoreactivity in the nucleus, perinuclear cytoplasm, and processes of neurons; some bright NSE-immunoreactive fibers and medium-intensity staining of the neuropil are also seen. C) Caudate nucleus (head): choline acetyltransferase (ChAT) immunoreactivity in the multipolar neuron and its processes. D) Thoracic sympathetic ganglion: tyrosine hydroxylase (rabbit polyclonal) immunoreactivity in most of large and small neurons, mainly in the cytoplasm, as well as in bundles of nerve fibers going alongside these neurons. E) Substantia nigra, pars compacta: tyrosine hydroxylase (mouse monoclonal) antibody labels many (but not all) nigral neurons. F) Nucleus ruber: NeuN-labeled neurons with highly stained nucleus and the perinuclear cytoplasm. G) Parietal cortex, layer III: Iba-1 distinctly labels multiple thin processes and some perikarya of microgliocytes. H) Cerebellum: strong calbindin immunostaining in the cytoplasm and dendrites of the Purkinje cells. I) Cerebellum: calretinin immunohistochemistry visualizes the unipolar brush cell, a rare sort of the large cerebellar interneurons in the granular layer. ${ }^{23} \mathrm{~J}$ ) Substantia nigra, pars reticulata: distinct synaptophysin immunoreactivity in the clusters of synapses alongside the neuronal and fiber plasmalemma. K) Cerebellar cortex: GAD65 immunostaining of the fine fiber nets in the granular layer, which localization coincides with the distribution of the glomeruli, the specific synaptic formations composed by the granular cell dendrites, mossy fibers, and axons of the Golgi cells. L) Nucleus ruber: GFAP distinctly labels the perinuclear cytoplasm and processes of fibrous astrocytes forming large nets in the neuropil. Preparations A-E), G-L) are counterstained with hematoxylin; F) with astra blue.

immunoreactivity was quite evident for the cell type and neurotransmitter markers used: only astroglia-like ramified cells were labeled with GFAP (Figure 1L), only a part of cell population in the area studied were labeled with tyrosine hydroxylase (Figure 1 D,E), and only some large neurons were choline acetyltransferaseimmunoreactive in the caudate nucleus (Figure 1C). The used antibodies were effective for all cortical and subcortical areas examined and in preparations obtained from one and the same brain (Figure 2).

Sections of the human brain fixed in $10 \%$ neutral buffered formalin showed good preservation of the nervous tissue in histological preparations (data not shown). However, results of immunostaining with the same antibodies were clearly worse with exception of GFAP (Figure 3).

\section{Discussion}

Our assessment of the ZEF for fixation of animal brain for further histological and immunohistochemical studies demonstrated high-quality results for many antibodies..$^{2433}$ The study reported here was carried out on post-mortal brains and demonstrated that the ZEF fixation results in superior preservation of the human brain tissue: no tissue shrinkage or distortion of cellular structure was observed, the cellular components retained in their native compartments and the cells were presented with a distinct and detailed microscopic appearance. The tinctorial properties of the ZEF-fixed human brain can be considered excellent: the Nissl-stained preparations produced superior view of all cell types in all the brain areas studied, regardless of whether they were stained with hematoxylin or astra blue. The same good results were obtained after luxol fast blue staining (Klüver-Barrera method) as well (data not shown).

Usage of the ZEF-fixed preparations for immunohistochemistry showed that a number of different antigens were present and preserved and that their immunohistochemical visualization was effective. The antigens used included markers of neurons (NeuN and NSE), astro- and microglia (GFAP and Iba-1, respectively), synaptic vesicles (synaptophysin), a protein of microtubules $\alpha$-tubulin, the neurotransmitter markers choline acetyltransferase, glutamic acid decarboxylase, and tyrosine hydroxylase typical for cholinergic, GABAergic, and catecholaminergic neurons, respectively as well as calcium-binding proteins calbindin and calretinin. The immunohistochemical technique revealed all the used antigens distinctly and with minimal background staining.

Examination of many specimens obtained 


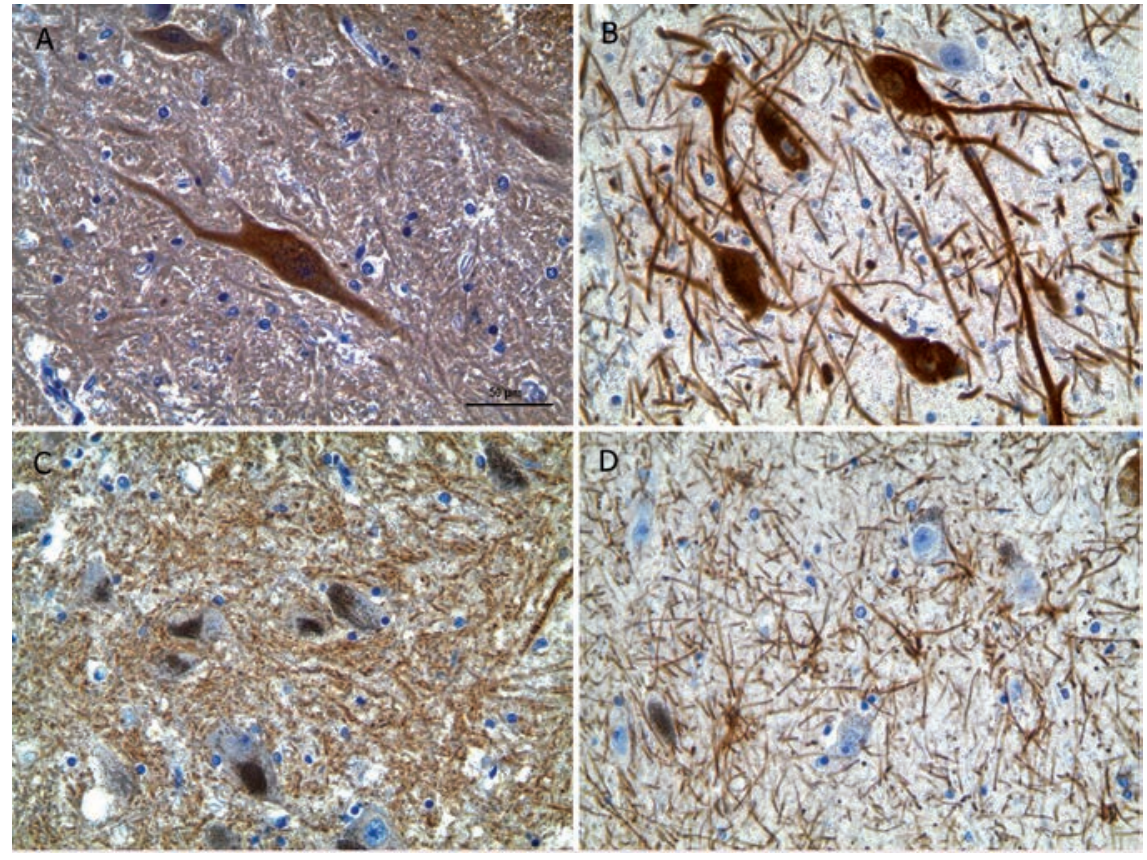

Figure 2. Immunohistochemistry for neuron-specific enolase (NSE), tyrosine hydroxylase (rabbit polyclonal), synaptophysin, and GFAP in the substantia nigra of one and the same brain (case No. 4). A) NSE. B) Tyrosine hydroxylase. C) Synaptophysin. D) GFAP. Intensive specific immunostaining of four randomly selected antigens; to be noted the absence of background staining; counterstaining with hematoxylin. Scale bars: $50 \mu \mathrm{m}$.
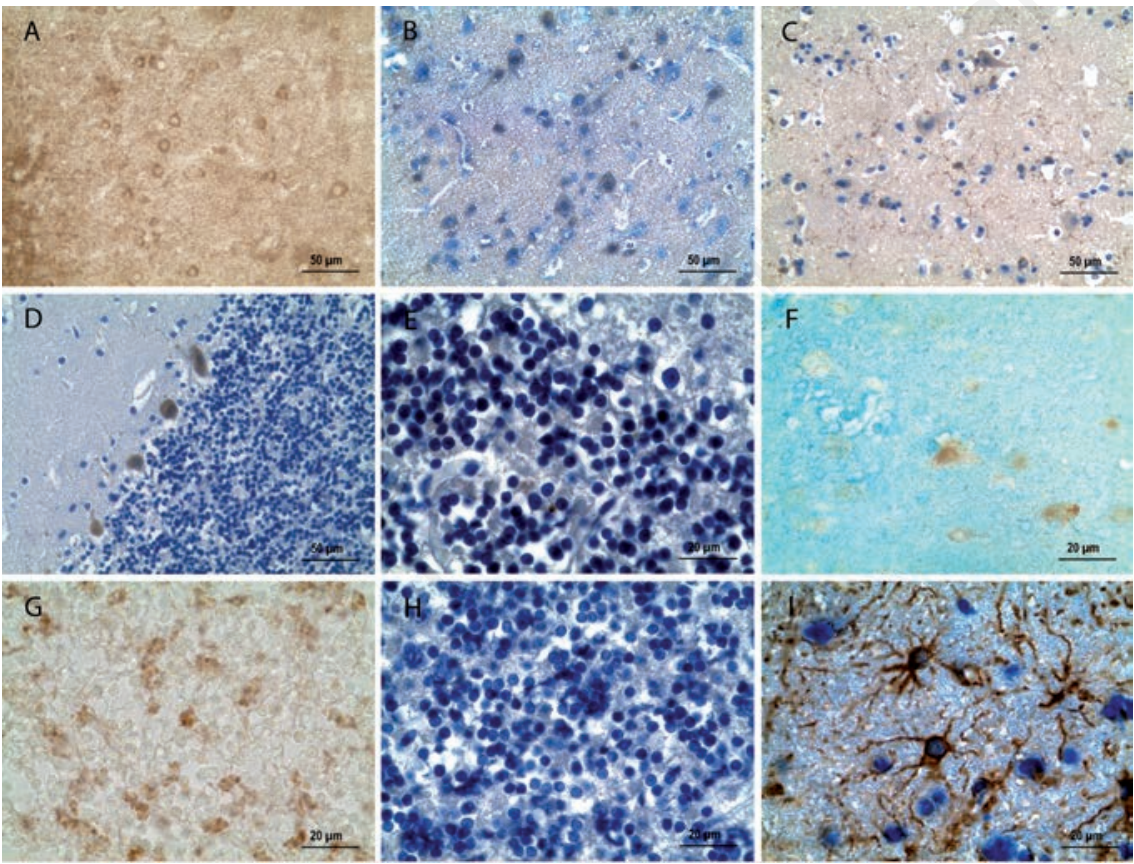

Figure 3. Examples of immunohistochemical staining of the human brain fixed in $10 \%$ neutral buffered formalin. A) Parietal cerebral cortex, layer III: $\alpha$-tubulin, weak immunopositive reaction in neurons virtually indistinguishable from the background. B) Parietal cerebral cortex, layer II-III: NSE, weak immunopositive reaction in some neurons. C) Parietal cerebral cortex, layer II-III: Iba-1, weak immunopositive reaction in microgliocytes. D) Cerebellar cortex: calbindin, weak immunopositive reaction in Purkinje cells. E) Cerebellar cortex: calretinin, negligible immunopositive reaction in cells. F) Parietal cerebral cortex, layer II: NeuN, weak immunopositive reaction in some neurons. G) Cerebellar cortex: synaptophysin, weak immunopositive reaction in glomeruli. H) Cerebellar cortex: GAD65, no immunopositive reaction in cerebellar cells. I) Parietal cerebral cortex, III layer: GFAP, intensive immunopositive reaction in astrocytes. Sections in panels $A$ ) and G): without counterstaining; B-E), H), and I): counterstained with hematoxylin; F) with astra blue. after fixation with ZEF showed greater sensitivity of the immunohistochemical reactions for most of the antigens studied than after use of other fixatives, particularly $10 \%$ formalin. ${ }^{33}$ Use of fluorescence and confocal laser microscopy methods for animal brain tissue fixed in the ZEF gives images of high quality. ${ }^{20,34,35}$ There was no significant increase in baseline autofluorescence as compared with alcohol and formalin fixation. Of importance is that the ZEF is an inexpensive and easy prepared fixative.

In conclusion, the obtained data indicate that sufficient antigens are preserved in the human brain fixed in the ZEF and that immunohistochemistry technique is applicable and effective for this material. Moreover, the ZEF fixative has potential for use in general histological practice, where detailed characterization of tissue morphology is needed.

\section{References}

1. Dapson RW. Macromolecular changes caused by formalin fixation and antigen retrieval. Biotech Histochem 2007;82:13340 .

2. Puchtler H, Meloan SN. On the chemistry of formaldehyde fixation and its effects on immunohistochemical reactions. Histochemistry 1985;82:201-4.

3. Webster JD, Miller MA, Dusold D, RamosVara J. Effects of prolonged formalin fixation on diagnostic immunohistochemistry in domestic animals. J Histochem Cytochem 2009;57:753-61.

4. Lykidis D, Van Noorden S, Armstrong A, Spencer-Dene B, Li J, Zhuang Z, et al. Novel zinc-based fixative for high quality DNA, RNA and protein analysis. Nucleic Acids Res 2007;35:e85.

5. Arnold MM, Srivastava S, Fredenburgh J, Stockard CR, Myers RB, Grizzle WE. Effects of fixation and tissue processing on immunohistochemical demonstration of specific antigens. Biotech Histochem 1996;71:224-30.

6. Sillevis Smitt PA, van der Loos C, Vianney de Jong JM, Troost D. Tissue fixation methods alter the immunohistochemical demonstrability of neurofilament proteins, synaptophysin, and glial fibrillary acidic protein in human cerebellum. Acta Histochem 1993;95:13-21.

7. Delfour C, Roger P, Bre C, Berthe ML, Rachiax P, Kalfa N, et al. RCL2, a new fixative, preserves morphology and nucleic acid integrity in paraffin-embedded breast carcinoma and microdissected breast tumor cells. J Mol Diagn 2006;8:157-69.

8. Gatta LB, Cadei M, Balzarini P, Castriciano 
S, Paroni R, Verzeletti A, et al. Application of alternative fixatives to formalin in diagnostic pathology. Eur J Histochem 2012; $56: \mathrm{e} 12$.

9. Gillespie JW, Best CJ, Bichsel VE, Cole KA, Greenhut SF, Hewitt SM, et al. Evaluation of non-formalin tissue fixation for molecular profiling studies. Amer J Pathol 2002; 160:449-57.

10. Klopfleisch R, von Deetzen M, Weiss AT, Weigner J, Weigner F, Plendl J, Gruber AD. Weigners fixative - an alternative to formalin fixation for histology with improved preservation of nucleic acids. Vet Pathol 2013;50:191-9.

11. Mueller C, Edmiston KH, Carpenter C, Gaffney E, Ryan C, Ward R, et al. One-step preservation of phosphoproteins and tissue morphology at room temperature for diagnostic and research specimens. PLoS One 2011;6:e23780.

12. Nietner T, Jarutat T, Mertens A. Systematic comparison of tissue fixation with alternative fixatives to conventional tissue fixation with buffered formalin in a xenograft-based model. Virchows Arch 2012;461:259-69.

13. Olert J, Wiedorn KH, Goldman T, Kühl H, Mehraein Y, Scherthan H, et al. HOPE fixation: a novel fixing method and paraffinembedding technique for human soft tissues. Pathol Res Practice 2001;197:823-6.

14. Rieger J, Twardziok S, Huenigen $\mathrm{H}$, Hirschberg RM, Plendl J. Porcine intestinal mast cells. Evaluation of different fixatives for histochemical staining techniques considering tissue shrinkage. Eur J Histochem 2013;57:e21.

15. Vincek V, Nassiri M, Nadji M, Morales AR. A tissue fixative that protects macromolecules (DNA, RNA, and protein) and histomorphology in clinical samples. Lab Invest 2003;83:1427-35.

16. Beckstead JH. A simple technique for preservation of fixation-sensitive antigens in paraffin-embedded tissues. J Histochem Cytochem 1994;42:1127-34.

17. Eltoum IE, Fredenburgh J, Grizzle W. Advanced concepts in fixation: 1 . Effects of fixation on immunohistochemistry, reversibility of fixation and recovery of proteins, nucleic acids, and other molecules from fixed and processed tissues. 2 .
Developmental methods of fixation. J Histotechnol 2001;2:201-10.

18. Hicks DJ, Johnson L, Mitchell SM, Gough J, Cooley WA, La Ragione RM, et al. Evaluation of zinc salt based fixatives for preserving antigenic determinants for immunohistochemical demonstration of murine immune system cell markers. Biotech Histochem 2006;81:23-30.

19. Lynn JA, Whitaker BP, Hladik CL, Robinson RJ, Joie JB, Stigliano WW, et al. Zinc isopropyl alcoholic unbuffered formalin as a postfixative for routine surgical pathology specimens. J Histotechnol 1994;17:105-9.

20. Ott SR. Confocal microscopy in large insect brains: zinc-formaldehyde fixation improves synapsin immunostaining and preservation of morphology in wholemounts. J Neurosci Methods 2008; 172:220-30.

21. Tome Y, Hirohashi S, Noguchi M, Shimosato Y. Preservation of cluster 1 small cell lung cancer antigen in zinc-formalin fixative and its application to immunohistological diagnosis. Histopathology 1990;16:469-74.

22. Wester K, Asplund A, Bäckvall H, Micke P, Derveniece A, Hartmane I, et al. Zincbased fixative improves preservation of genomic DNA and proteins in histoprocessing of human tissues. Lab Invest 2003;83:889-99.

23. Ambrosi G, Flace P, Lorusso L, Girolamo F, Rizzi A, Bosco L, et al. Non-traditional large neurons in the granular layer of the cerebellar cortex. Eur J Histochem 2007;51(Suppl.1):59-64.

24. Chumasov EI, Korzhevskii DE, Petrova ES, Sapronov NS, Kuznetsova NN. Glial reaction of the subventricular zone of the telencephalon of the rat brain on modeling of Alzheimer's disease. Neurosci Behav Physiol 2012;42:67-71.

25. Grigoriev IP, Vasilenko MS, Sukhorukova EG, Korzhevskii DE. Use of different antibodies to tyrosine hydroxylase to study catecholaminergic systems in the mammalian brain. Neurosci Behav Physiol 2012;42:210-3.

26. Kirik OV, Alekseeva OS, Moskvin AN, Korzhevskii DE. Effects of hyperbaric oxygenation on subependymal microglia of the rat brain. J Evol Biochem Physiol 2014;50:353-6.

27. Korzhevskii DÉ, Gilyarov AV, Kirik OV, Lentsman MV, Vlasov TD. Induction of nestin synthesis in rat brain cells by ischemic damage. Neurosci Behav Physiol 2008;38:139-43.

28. Korzhevskii DE, Gilyarov AV, Otellin VA, Lentsman MV, Kostkin VB. Morphological manifestations of local functional activation of astrocytes induced by transient global cerebral ischemia. J Evol Biochem Physiol 2007;43:505-8.

29. Korzhevskii DE, Kirik OV, Baisa AE, Vlasov TD. Simulation of unilateral ischemic injury to the striatal neurons inflicted by short-term occlusion of the middle cerebral artery. Bull Exp Biol Med 2009;147: 255-6.

30. Korzhevskii DE, Kirik OV, Lentsman MV, Otellin VA. Morphological types of activated microglial cells in the hippocampus present after transient total cerebral ischemia. Neurosci Behav Physiol 2013; 43:861-4.

31. Korzhevskii DE, Kirik 0, Sukhorukova E. Immunocytochemistry of microglial cells, pp. 209-24. In: A. Merighi A, L. Lossi L, eds., Immunocytochemistry and related techniques. New York: Springer; 2015.

32. Suchorukova EG, Kirik OV, Korzhevskii DE. The use of immunohistochemical method for detection of brain microglia in paraffin sections. Bull Exp Biol Med 2010;149:768-70.

33. Korzhevskii DE, Sukhorukova EG, Gilerovich EG, Petrova ES, Kirik OV, Grigor'ev IP. Advantages and disadvantages of zinc-ethanol-formaldehyde as a fixative for immunocytochemical studies and confocal laser microscopy. Neurosci Behav Physiol 2014;44:542-5.

34. Kirik OV, Sukhorukova EG, Korzhevski DE. Calcium-binding protein Iba-1/AIF-1 in rat brain cells. Neurosci Behav Physiol 2011;41:149-52.

35. Korzhevski DE, Sukhorukova EG, Kirik OV, Alekseeva OS. Astrocytes of the subventricular zone of the telencephalon. Neurosci Behav Physiol 2012;42:789-91. 